\title{
Fenologia reprodutiva do patauazeiro (Oenocarpus bataua Mart.) cultivado nas
}

\section{condições de Belém-PA}

\author{
Reproductive Phenology of the patauá palm (Oenocarpus bataua Mart.) cultivated under the \\ conditions of Belém-PA
}

Fenología reproductiva de seje (Oenocarpus bataua Mart.) cultivado en las condiciones de Belém-

\author{
Alynne Regina Nazaré Alves Maciel \\ ORCID: https://orcid.org/0000-0001-7812-4255 \\ Universidade Federal Rural da Amazônia, Brasil \\ E-mail: alynnemaciel10@gmail.com \\ Maria do Socorro Padilha de Oliveira \\ ORCID: https://orcid.org/0000-0002-4753-2018 \\ Embrapa Amazônia Oriental, Brasil \\ E-mail: socorro-padilha.oliveira@embrapa.br \\ Camila Pinto Brandão \\ ORCID: https://orcid.org/0000-0003-4658-1253 \\ Universidade Federal Rural da Amazônia, Brasil \\ E-mail: brandaopcamila@gmail.com \\ Renan de Freitas Mira \\ ORCID: https://orcid.org/0000-0003-2065-7141 \\ Universidade Federal Rural da Amazônia, Brasil \\ E-mail: renanfmufra@gmail.com
}

\begin{abstract}
Resumo
O trabalho teve por objetivo avaliar a fenologia reprodutiva do patauazeiro cultivado nas condições de Belém, PA. Foi realizado o monitoramento mensal em 163 plantas em plena fase reprodutiva do Banco Ativo de Germoplasma da Embrapa Amazônia Oriental, por 55 meses com base em três eventos de floração e quatro de frutificação e suas interações com seis variáveis meteorológicas. Calculou-se a taxa ocorrência e a sincronia de cada evento, além da correlação simples e da análise de componentes principais entre os eventos e as variáveis meteorológicas. Os eventos de floração e de frutificação ocorreram em todos os meses, com taxas variando de $0,6 \%$ (inflorescência seca) a $58 \%$ (emissão de brácteas). As fenofases mais frequentes foram a emissão de brácteas, inflorescências em floração e cachos com frutos imaturos. Cinco eventos foram assincrônicos e dois tiveram pouca sincronia, como a fenofases de emissão de brácteas e cacho com frutos imaturos. O pico da floração ocorreu de outubro a dezembro e o da frutificação de novembro a fevereiro. A maioria dos eventos foram poucos influenciados pelas variáveis climatológicas. Pode-se considerar que, nas condições do estudo, o patauazeiro apresenta eventos fenológicos reprodutivos em todos os meses, sendo assincrônicos e com picos de floração e frutificação sobrepostos.
\end{abstract}

Palavras-chave: Oenocarpus; Sincronia; Fenofases; Correlação de Pearson; Padrão fenológico.

\begin{abstract}
This paper aimed to evaluate the reproductive phenology of patauá palm cultivated in Belém, Pará, Brazil. Monthly monitoring carried out on 163 plants in the full reproductive phase of the Active Germplasm Bank of Embrapa Amazônia Oriental for 55 months based on three flowering and four fruiting events and their interactions with six meteorological variables. The occurrence rate and the synchrony of each event calculated, in addition to the simple correlation and the principal components analysis between the events and the meteorological variables. Flowering and fruiting events occurred every month, with rates ranging from $0.6 \%$ (dry inflorescence) to $58 \%$ (bract emission). The most frequent phenophases were the emission of bracts, inflorescences in flowering and bunches with immature fruits. Five events were asynchronous, and two had little synchrony, such as the phenophases of emission of bracts and bunch with immature fruits. The peak of flowering occurred from October to December and the fruiting from November to February. Most of the events were few influenced by the climatological variables. It can considered that, in the conditions of the study, the patauá palm presents reproductive phenological events in all months, being asynchronous and with overlapping flowering and fruiting peaks.
\end{abstract}

Keywords: Oenocarpus; Synchrony; Phenophases; Pearson correlation; Phenological pattern. 


\begin{abstract}
Resumen
El objetivo del trabajo fue evaluar la fenología reproductiva de seje cultivado en las condiciones de Belém, PA. Se realizó un monitoreo mensual en 163 plantas en la fase reproductiva del Banco Activo de Germoplasma de Embrapa Amazonía Oriental, durante 55 meses, con base en tres eventos de floración y cuatro fructificación y sus interacciones con seis variables meteorológicas. Se calculó la tasa de ocurrencia y sincronía de cada evento, además de la correlación simple y análisis de componentes principales entre los eventos y las variables meteorológicas. Los eventos de floración y fructificación ocurrieron en todos los meses, con tasas que variaron de $0.6 \%$ (inflorescencia seca) a $58 \%$ (emisión de brácteas). Las fenofases más frecuentes fueron la emisión de brácteas, inflorescencias florales y racimos con frutos inmaduros. Cinco eventos fueron asincrónicos y dos tuvieron poca sincronía, como fenofases de emisión de brácteas y racimo con frutos inmaduros. El pico de floración se produjo de octubre a diciembre y la fructificación de noviembre a febrero. La mayoría de los eventos estuvieron poco influenciados por variables climatológicas. Se puede considerar que, en las condiciones del estudio, el seje presenta eventos fenológicos reproductivos en todos los meses, siendo asincrónico y con picos de floración y fructificación superpuestos.
\end{abstract}

Palabras clave: Oenocarpus; Sincronía; Fenofases; Correlación de Pearson; Patrón fenológico.

\title{
1. Introdução
}

O patauazeiro (Oenocarpus bataua Mart.) é uma palmeira nativa de ocorrência natural na Amazônia que apresenta uso diversificado, mas suas potencialidades econômicas estão voltadas aos frutos, seja no processamento da polpa ou na extração de óleo de excelente qualidade para uso nas indústrias farmacêutica, cosmética e alimentícia, por ser similar ao de oliva (Gomes-Silva et al., 2004; Furlan Júnior et al., 2006.). Os produtos obtidos de seus frutos possuem excelentes qualidades nutricionais, com ácidos graxos de alta insaturação, rico em aminoácidos essenciais, além de serem fontes de compostos antioxidantes (Serra, et al., 2019; Mushtaq et al., 2019). Entretanto, a produção de frutos que abastece esses mercados ainda provém do extrativismo praticado no Pará e nos demais estados dessa região onde estão seus maiores consumidores, sendo irregular e de baixa produtividade. Atualmente, a procura por produtos naturais e de fontes renováveis, que venham satisfazer as necessidades do consumidor sem prejudicar as futuras gerações tem aumentado remetendo a necessidade da geração de conhecimentos que possam orientar o manejo adequado dessa palmeira, como os eventos fenológicos.

Os eventos fenológicos são essenciais no manejo das populações naturais de qualquer espécie, por definir a necessidade ecoclimática, o período crítico, a precocidade e o zoneamento, funcionando como indicador de danos ambientais, impactando diretamente no fornecimento de serviços ecossistêmicos para sociedade (Costa \& lameira,2021). Logo, podem auxiliar na exploração sustentável da espécie, aumentando a capacidade de suporte para a demanda de frutos (Homma, 2014; Izasa et al., 2016). Vale ressaltar que o conhecimento desses eventos também pode auxiliar na tomada de decisão sobre o manejo nos cultivos racionais, além do uso no entendimento da ecologia de ecossistemas, uma vez que as fenofases de floração e frutificação estão associadas aos processos de interação planta-animal em relação à polinização, dispersão e predação de sementes (Jardim \& Kageyama, 1994; Mantovani et al., 2003; Morellato et al., 2016).

As fenofases de floração, de frutificação e suas associações com os eventos meteorológicos podem orientar as estratégias de manejo, coleta de sementes, assim como definir o período de safra de espécies de interesse (Morellato et al., 2016). A avaliação desses eventos pode ser feita em diferentes intervalos, sendo feita frequentemente por observações semanais, quinzenais ou mensais (Mantovani et al., 2003). Em palmeiras o intervalo mais comum é o monitoramento mensal (Ruiz \& Alencar, 2004, Pires et al., 2016; Rojas-Robles \& Stiles, 2009; Mendes et al., 2017). Na determinação da associação das variáveis climáticas com as fases fenológicas da planta são utilizadas correlações múltipla ou simples, nesse último caso a de Pearson $(\rho)$, que mede a relação linear entre as variáveis quantitativas (Figueiredo Filho \& Silva Junior, 2009).

Estudos envolvendo os aspectos fenológicos do patauazeiro são escassos e os disponíveis foram realizados em populações naturais na Amazônia equatoriana (Miller, 2002), em Manaus, AM (Ruiz \& Alencar, 2004), no Acre (GomesSilva, 2004) e na Colômbia (Collazos \& Mejía, 1988; Rojas-Robles \& Stiles, 2009; Cifuentes et al., 2010), todos enfatizando o 
longo período para o amadurecimento dos frutos, a sobreposição das fases de floração e frutificação, a irregularidade da produção de frutos com o impedimento da definição do padrão fenológico para a espécie. Contudo, na Amazônia Oriental esses estudos são inexistentes, seja em populações naturais ou em condições de cultivo, o que dificulta a obtenção de subsídios para seu manejo, tratos culturais, além de outros, sobretudo aqueles que visem à conservação adequada da espécie. Nas condições de Belém, PA há uma área experimental da espécie instalada na Embrapa Amazônia Oriental, que vem sendo utilizada na geração de avanços no conhecimento e subsídios para a sua domesticação, o Banco Ativo de Germoplasma de Patauá e que pode ser útil na obtenção desses eventos (Oliveira et al, 1991; ALELO, 2020).

Este trabalho teve por objetivo avaliar a fenologia reprodutiva do patauazeiro cultivado nas condições de Belém, PA, com base nas fenofases de floração e de frutificação.

\section{Metodologia}

\section{a) Localização da área de estudo}

O estudo científico, de natureza quantitativa, segundo Pereira (2018) foi realizado em 163 patauazeiros, em plena fase reprodutiva, existentes em uma área experimental da Embrapa Amazônia Oriental (Figura 1), denominada de Banco Ativo de Germoplasma, BAG Patauá, localizada em Belém, PA (latitude de 1²6'00”'S e longitude de 48²4'30”W), cujo clima local é o $\mathrm{Af}_{\mathrm{i}}$ pela classificação de Köppen. A área foi instalada em fevereiro de 1986, em condições de terra firme, com solo do tipo Latossolo Amarelo Textura média, com as plantas espaçadas de $7 \mathrm{~m}$ por $7 \mathrm{~m}$, sendo mantidas com tratos culturais envolvendo roçagem mecanizada, coroamento, limpeza das plantas, adubação química e orgânica, em frequência trimestral.

Figura 1. Localização da área do estudo, Banco Ativo de Germoplasma (BAG) de patauá e distribuição das 163 plantas avaliadas.
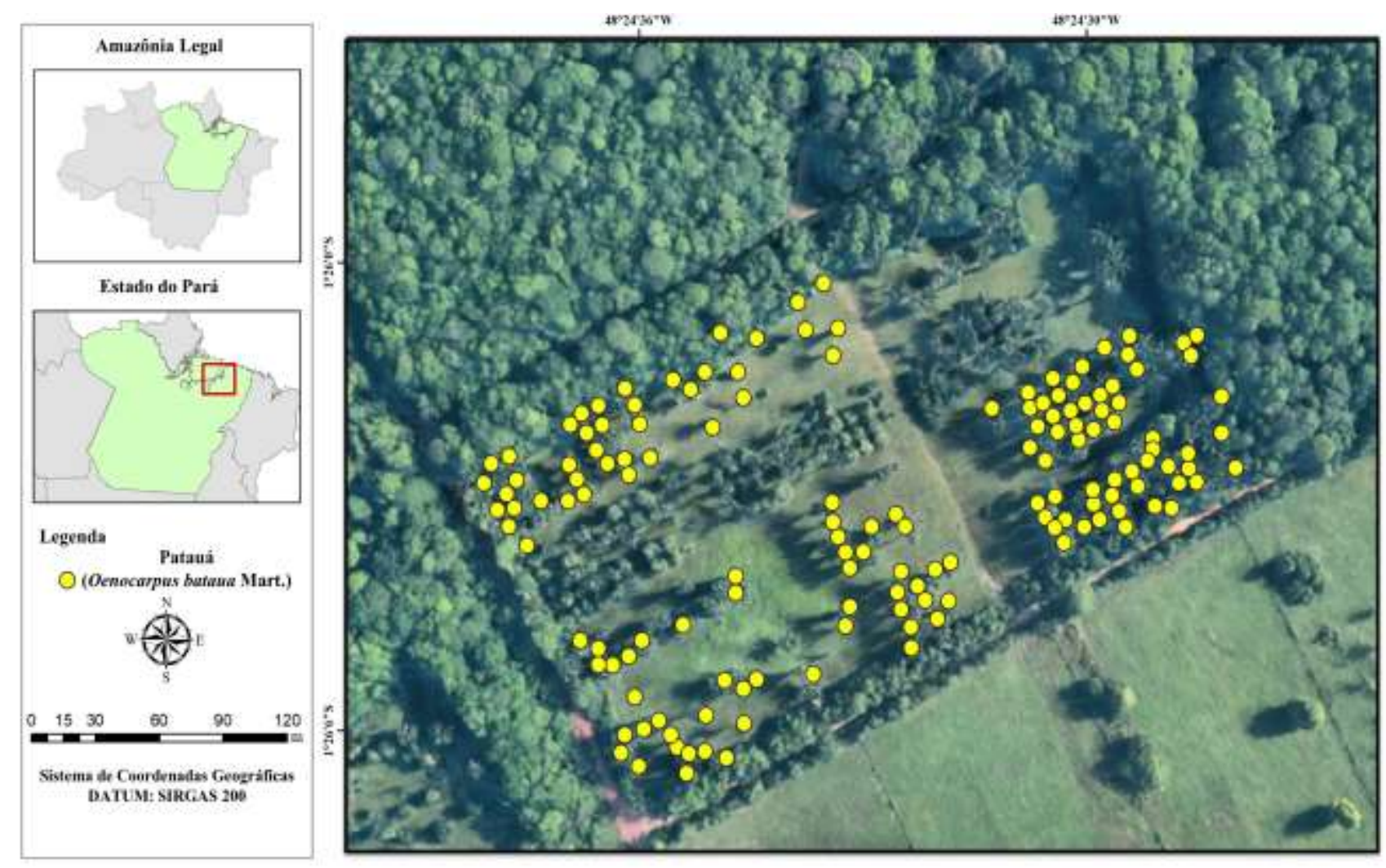

Fonte: Autores (2021). 


\section{b) Dados climáticos}

Seis variáveis meteorológicas foram obtidas no site do Instituto Nacional de Metrologia (INMET, 2019) para o período avaliado, de forma a serem correlacionadas com as fenológicas, sendo elas: precipitação pluviométrica (PREC), insolação (INSO), umidade relativa do ar (URA) e temperaturas máxima (TMX), mínima (TMN) e média (TMD), representados pelas médias mensais.

\section{c) Dados fenológicos}

Os eventos fenológicos foram observados mensalmente, no período de setembro/2014 a março/2019, totalizando 55 meses. A metodologia usada na coleta dos dados seguiu a de Ruiz e Alencar (2004), pela aplicação do método quantitativo que consiste no acompanhamento individual de cada planta realizando a contagem total do evento observado em campo (D'EçaNeves; Morellato, 2004).

Em cada patauazeiro foram avaliados sete eventos fenológicos (Figura 2), envolvendo três de floração: emissão de brácteas (BRA), presença do ramo florífero na condição de bráctea ainda fechada em diferentes estágios de desenvolvimento; inflorescências em floração (IF), presença de inflorescências abertas em diferentes estágios de floração, ou seja na fase masculina ou feminina; inflorescências secas (IS), presença de inflorescências secas (cujas flores abortaram ou caíram); e quatro de frutificação: presença de cachos recém-fecundados (CRF), cachos cujas flores foram fecundadas; de cachos com frutos imaturos (CFI), cachos com frutos em diferentes estágios de desenvolvimento e de coloração verde a imaturos); de cachos com frutos maduros (CFM), cujos frutos já atingiram a coloração violácea opaca; de cachos secos (CFS) compreendendo os cachos cujos frutos caíram ou secaram ao longo do desenvolvimento.

\section{d) Análise dos dados}

Com dados obtidos foram calculadas inicialmente, as porcentagens de ocorrência de cada evento fenológico por indivíduo para cada mês. O cálculo consistiu na divisão do número de indivíduos que apresentaram o evento, pelo número total de indivíduos acompanhados, multiplicado por 100. Em seguida, foi calculado o Índice de Atividade (em porcentagem), a partir da média de cada mês do ano para cada fenofase, para estimar o grau de sincronia, considerando assincrônico ( $<20 \%$ de ocorrência), pouco sincrônico (de $20 \%$ a $60 \%$ de ocorrência) e sincrônico ( $>60 \%$ de ocorrência), conforme sugerido por Bencke e Morellato (2002).

Com base na soma dos índices de atividades dos eventos BRA e IF, como também CRF, CI e CM foi estimado o padrão fenológico de floração e de frutificação da espécie na condição do estudo. A parti do valor médio geral da ocorrência das fenofases de floração e frutificação dos 55 meses de avaliados, os valores superiores à média foram considerados os meses de ocorrência padrão da fase, sendo possível a construção padrão fenológico da espécie para o município.

Foram estimados os coeficientes de correlação simples de Pearson (r) entre as porcentagens de ocorrência dos sete eventos fenológicos e as seis variáveis meteorológicas. A análise foi realizada no programa GENES versão 7.0 (Cruz, 2006). Para esta avaliação considerou-se como relação positiva: $r=1$, quando a relação é perfeita positiva entre as duas variáveis; relação negativa: $r=-1$, quando a relação é perfeita negativa isto é, se uma aumenta, a outra sempre diminui; e relação difusa ou não linear, quando $r=0$, quando as duas variáveis não dependem linearmente uma da outra (Figueiredo Filho \& Silva Júnior, 2009; Costa e Lameira, 2021 ). O nível de significância foi obtido com base no teste $t$ de Student. 
Figura 2. Eventos de floração e frutificação acompanhados nos 163 patauazeiros (O. bataua) cultivados em área experimental da Embrapa Amazônia Oriental, em Belém, PA.

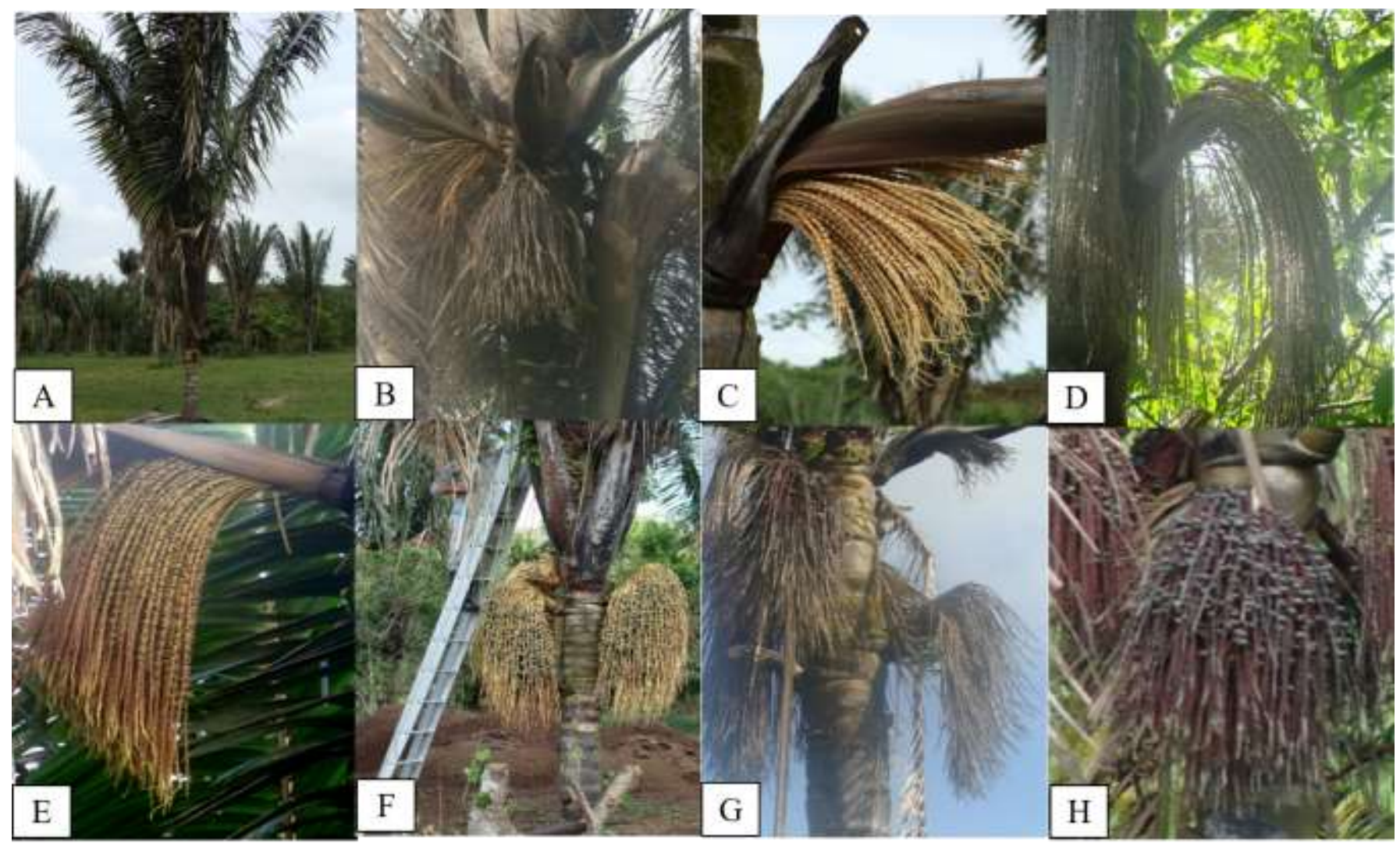

A. Planta de O. bataua; B. emissão de bráctea (BRA); C. inflorescência em floração (IF); D. inflorescência seca (IS); E. cacho recém fecundado (CRF); F. cacho frutos imaturos (CFI); G. cacho maduro (CFM); H. cacho seco.

Fonte: Maria do Socorro Padilha (2021).

Foi realizada, também, a análise de componentes principais envolvendo os dados das porcentagens de ocorrência dos sete eventos fenológicos e os das seis variáveis meteorológicas, no software GENES versão 7.0, com vista a determinar as porcentagens de contribuição de cada variável nos eventos fenológicos, assim como a representação gráfica da dispersão das variáveis em eixo cartesiano, conforme Ruiz e Alencar (2004).

\section{Resultados e Discussão}

O regime de precipitação pluvial durante os 55 meses apresentou como período mais chuvoso de dezembro a maio, com pico no mês de março (587 mm), alcançando em março/2017 até $670 \mathrm{~mm}$ (Figura 3). De setembro a novembro ocorreu o período menos chuvoso, com registros apenas 26, mm/mensal (out/2015), ocorrendo a menor pluviosidade em média no mês de setembro. Nesse mesmo período foi constatado aumento em horas de insolação, chegando até 278 horas/mensal, em agosto de 2015. De setembro a novembro considerado o período de estiagem, o qual foram observados baixos valores para precipitação e umidade relativa do ar, com pico de horas de insolação. As temperaturas foram sempre elevadas, variando em média de $25^{\circ} \mathrm{C}$ a $32{ }^{\circ} \mathrm{C}$. 
Figura 3. Distribuição mensal de seis variáveis meteorológicas: Insolação (INS), precipitação (PREC), Umidade relativa do ar (URA), temperatura máxima (TMAX), mínima (TMIN) e média (TMED) para os 55 meses de avaliação no local do estudo.

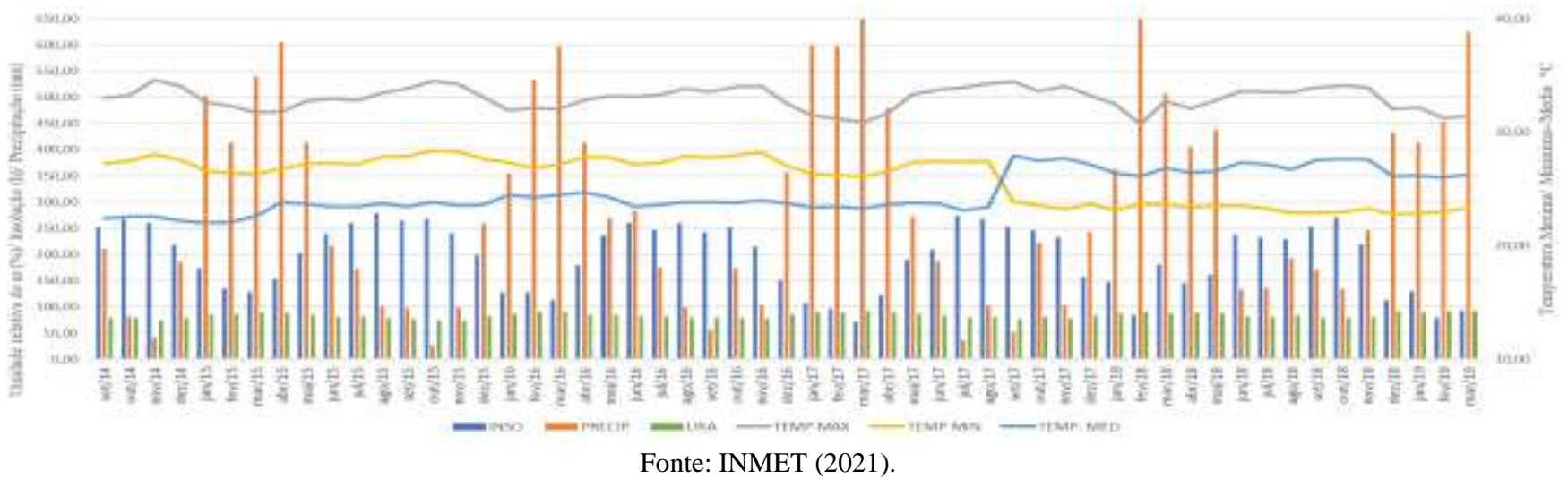

Os eventos de floração constam na Figura 4. A emissão de bráctea (BRA), primeiro evento fenológico de floração, teve ocorrência ao longo de todo o período avaliado (Figura 4A), variando de $22 \%$ a $59 \%$. As menores taxas foram registradas nos meses de jan/15, mai/17 e fev/18, enquanto os picos de lançamentos nos meses de outubro/2014 e maio/2018, indicando que este evento seja mais frequente no período menos chuvoso e na estiagem. A presença de inflorescências em floração (IF) foi evidenciada também, em todos os meses de avaliação (Figura 4B), porém em menores porcentagens (8\% 27 $\%)$, com os menores registros ocorrendo nos meses de mai/15 e fev/18, enquanto as maiores taxas nos meses de out e nov/14 e também nos meses de novembro e dezembro dos anos de 2015, 2016 e 2017, coincidindo com o fim do período de estiagem e início do chuvoso. Nos anos posteriores (2018 e 2019) o percentual de inflorescência em floração foi abaixo de $20 \%$. Quanto ao evento inflorescência seca (IS), este foi pouco registrado em quase todo o período (até 10\%), indicando que a maioria das inflorescências que entraram em floração obtiveram êxito na fecundação flores (Figura 4C). Entretanto, nos meses de junho a setembro/2018 e de novembro/2018 a março/2019 ocorreram registros de até $30 \%$ de inflorescências secas.

Foi constatado que as maiores ocorrências das fenofases de floração, a exemplo da emissão de bráctea (BRA) e da inflorescência em floração (IF) no patauzeiro, foram observadas nos meses de baixa precipitação pluviométrica. Ruiz e Alencar (2004) ao analisarem esses eventos em população natural de patauazeiro nas condições de Manaus (AM), registraram taxa de 13,9 \% para a emissão de bráctea, valor menor que o encontrado no presente estudo (>50\%), o que pode estar relacionado com fatores endógenos da espécie (fisiológicas, nutricionais, edáficas, genéticas, modo de reprodução). Para esses autores os altos percentuais de emissão de bráctea podem ser explicados pelo longo período do evento na planta, pois quando o indivíduo começa a emitir inflorescências, a maioria das novas folhas já possui um novo botão floral em formação. O evento inflorescência seca, foi observado com mais frequência dentre os anos 2018/2019, registro de 30\%, o que pode ter sido causado pelo aumento da temperatura média anual, fatores bióticos como baixa presença de agentes polinizadores. De modo geral, pode se considerar que os eventos fenológicos de floração do patauazeiro são de ocorrência em período de baixa pluviosidade.

Eventos fenológicos realizados outras palmeiras arbóreas apresentaram resultados concordantes e discordantes com o referido estudo. Por exemplo, Pires et al. (2016) ao estudarem eventos fenológicos em uma população de inajazeiro (Attalea maripa) no Pará, também verificaram a maior ocorrência das fenofases de floração em nos meses de baixa pluviosidade. Silva e Reis (2018) em palmiteiro (Euterpe Edulis) relataram a floração com maior intensidade no período seco (dezembro e janeiro) semelhante ao encontrado da palmeira em questão. Em Attalea phalerata, também foi evidenciado o pico de floração no final da estação seca (Lima et al. 2018). 
Figura 4. Porcentagens de ocorrência dos três eventos fenológicos de floração: emissão de brácteas (BRA), inflorescências em floração (IF) e inflorescências secas (IS), no período de setembro/2014 a março/2019, em patauazeiro (O. bataua) cultivado nas condições de Belém, PA.

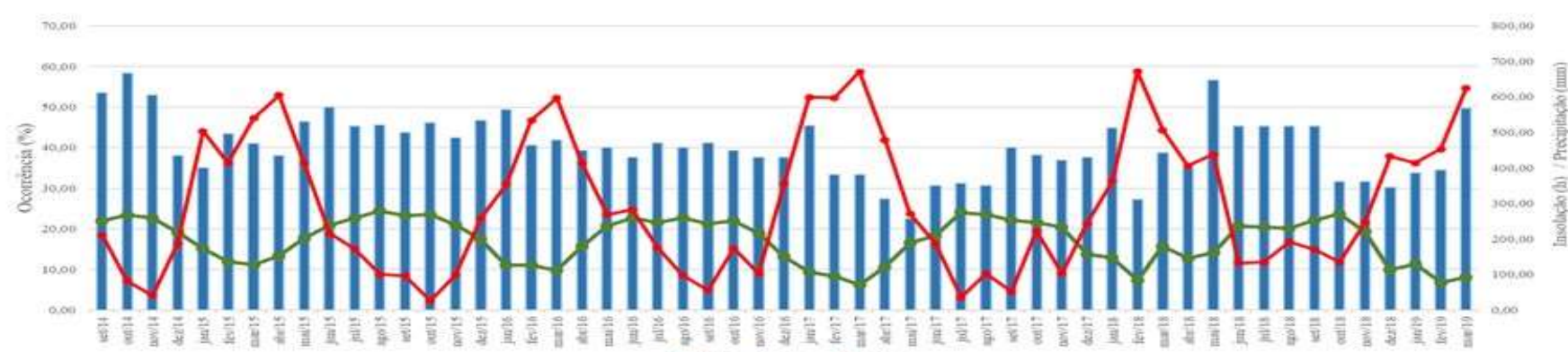

A

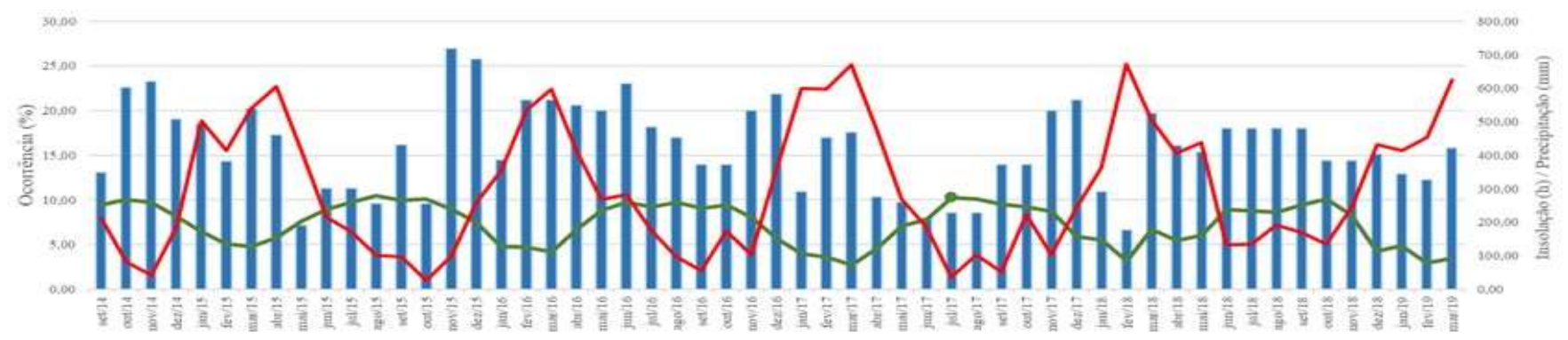

B

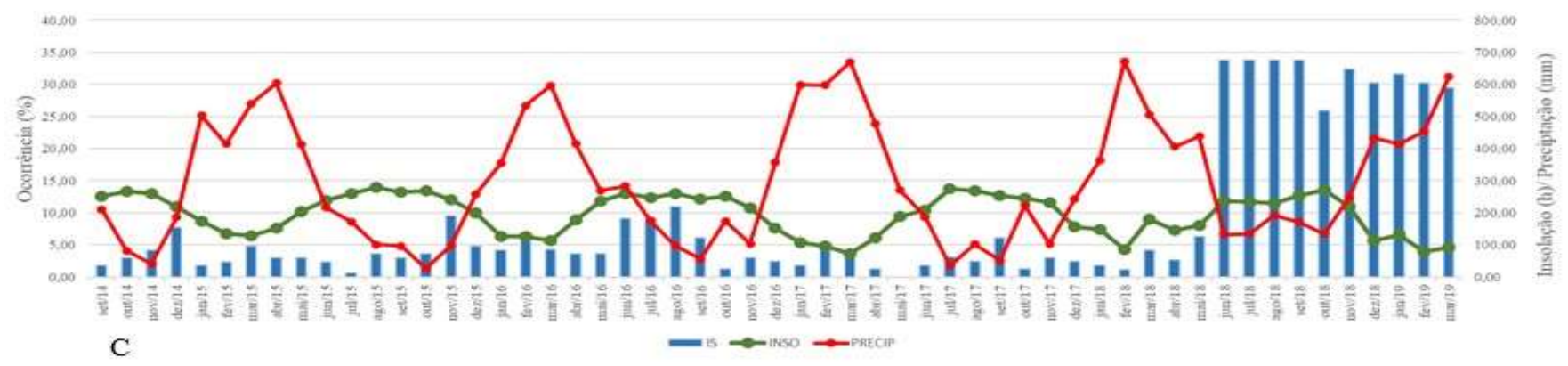

Fonte: Autores (2021).

No caso das fenofases de frutificação, o evento cacho recém-fecundado (CRF) apresentou baixas taxas ao longo das avaliações (0\% a 20\%), com as maiores porcentagens de ocorrência sendo observadas de novembro/2018 a março/2019 (Figura 5A). O evento cacho com frutos imaturos (CFI) foi a fenofase de maior registro ao longo do período, com taxas variando de $24 \%$ a $50 \%$ (Figura 5B). As menores ocorrências foram registradas nos meses de jan/15 e fev/18, com 27 \% e 24 $\%$, respectivamente. Enquanto as maiores porcentagens ocorreram de agosto a outubro de 2015, coincidindo com o período de baixa precipitação média mensal (Figura 5). A fenofase cacho com frutos maduros (CFM) teve baixa taxa de ocorrência (0\% a $5 \%$ ) em quase todo o período do estudo, com registro de ascensão de nov/14 a jan/15 (8 \%) e de dez/18 a março/19, apresentando nesse último período taxa acima de $15 \%$, ambos coincidindo com final do período seco e inicio do chuvoso (Figura 5C). A ocorrência do evento cacho seco (CS), também apresentou baixas taxas (1 \% a $30 \%)$, com as maiores porcentagens sendo registradas nos meses de setembro/2014 e maio/2018 (Figura 5D). Vale ressaltar que este foi o evento com maior flutuação, em grande parte do período avaliado as taxas não ultrapassaram $15 \%$. 
Figura 5. Porcentagens de ocorrência dos quatro eventos fenológicos de frutificação: cacho recém-fecundado (CRF), cacho com frutos imaturos (CFI), cacho com frutos maduros (CFM) e cacho seco (CS), no período de setembro/2014 a março/2019, em patauazeiro (O. bataua) cultivado nas condições de Belém, PA.
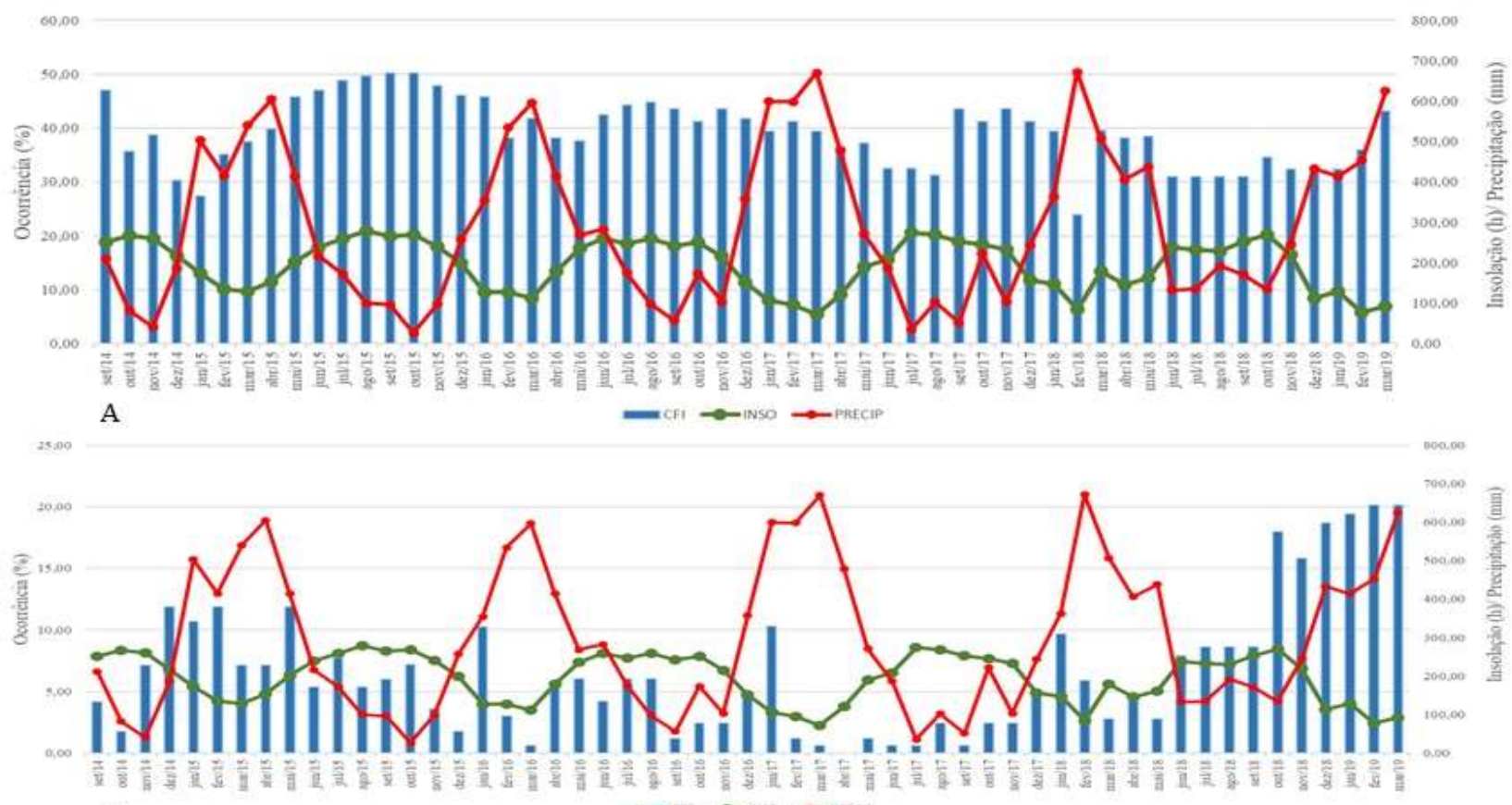

B
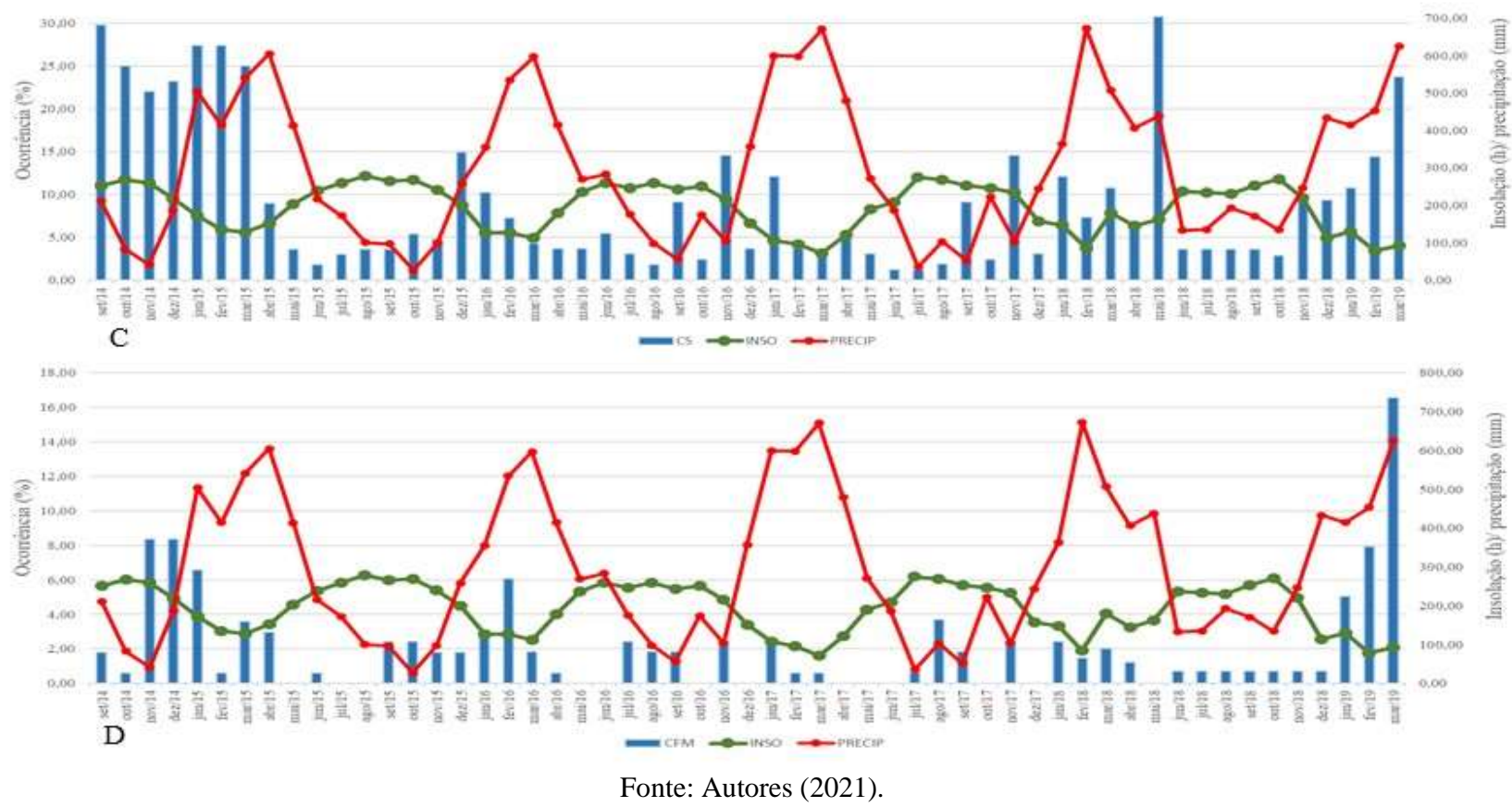

No que tange aos eventos fenológicos de frutificação (Figura 5A), a fenofase cacho recém fecundado (CRF) foi mais frequente no período seco, o que condiz com transição do final da floração e início da frutificação da espécie. Apesar das baixas ocorrências deste evento na maioria dos meses $(0,6 \%$ a $11 \%)$, pode-se considerar que houve boa distribuição na formação de frutos ao longo do ano. Já as fenofases seguintes (cacho com frutos imaturos e cacho com frutos maduros), que envolvem do desenvolvimento a maturação dos frutos foram mais presentes no período da estação chuvosa. Pires et al. (2016) também relataram ocorrência de cachos com frutos verdes mais intensos em período chuvoso. 
Quanto ao evento cacho com frutos maduros (CM) resultados similares foram encontrados para a espécie nas condições naturais da Colômbia, onde o pico desse evento não ultrapassou $12 \%$ na safra, sendo considerada como de produção supra anual (Rojas-Robles; Stiles, 2009). Esta fenofase em outras palmeiras como o babaçu (Attalea speciosa Mart.) e o buriti (Mauritia flexuosa L.f) ocorrem o ano todo, com pico no período de transição climática (Lima et al., 2018; Mendes et al., 2016). Duarte (2015) ressalta que a disponibilidade dos frutos ao longo do ano é um fator importante contribuinte para o fluxo gênico da espécie. Lima et al. (2018) sugeriram que este longo período de maturação não está relacionado apenas aos eventos climáticos, mas também com o ritmo fisiológico de longo prazo dessas espécies. Já o evento cacho seco (CS) este pode estar relacionado ao fato da permanência do cacho no estipe por longo período de tempo, ocasionado pela queda de frutos. Logo, pode-se considerar que o patauazeiro apresente um período muito longo entre a fecundação das flores e a maturação dos frutos, alcançando de 36 a 48 meses (Ruiz; Alencar, 2004; Miranda et al., 2008; Rojas-Robles; Stiles, 2009; Cifuentes et al., 2010). Nesse contexto acredita-se que os eventos de frutificação no patauazeiro são mais frequentes no período chuvoso.

Em relação à análise do índice de atividade de cada fenofase foi verificado que a espécie pode ser classificada como assincrônica (Tabela 1), uma vez que a maioria das fenofases apresentou baixa sincronia, com menos de 20 \% do índice de atividade, exceção feita apenas para os eventos emissão de brácteas (BRA) e cacho com frutos imaturo (CFI), que foram classificados como pouco sincrônicos, por apresentarem índices de atividades variando de 20 a $60 \%$, conforme classificação de Bencke e Morellato (2002).

Tabela 1. Porcentagens de ocorrência médias e grau de sincronia para sete eventos fenológicos avaliados em patauazeiro $(O$. bataua) cultivado nas condições de Belém, PA.

\begin{tabular}{lccc}
\hline \multirow{2}{*}{ Eventos } & $\begin{array}{c}\text { Taxa média ocorrência } \\
(\boldsymbol{\%})\end{array}$ & $\begin{array}{c}\text { Índice de atividade } \\
(\boldsymbol{\%})\end{array}$ & Grau de sincronia $^{\mathbf{1}^{\mathbf{n}}}$ \\
\hline Emissão de brácteas (BRA) & 40,3 & $20-60$ & Pouco sincrônico \\
Inflorescências em floração (IF) & 15,9 & $>20$ & Assincrônico \\
Inflorescências secas (IS) & 8,8 & $>20$ & Assincrônico \\
Cachos recém fecundados (CRF) & 6,6 & $>20$ & Assincrônico \\
Cachos imaturos (CI) & 39,2 & $20-60$ & Pouco sincrônico \\
Cachos maduros (CM) & 2,1 & $>20$ & Assincrônico \\
Cachos secos (CS) & 9,3 & $>20$ & Assincrônico \\
\hline
\end{tabular}

Fonte: Bencke e Morellato (2002).

As correlações indicaram a influência das variáveis meteorológicas em dois eventos de floração (BRA e IS) e três de frutificação (CRF, CFI e CS), porém de direção e magnitudes variáveis (Tabela 2). A temperatura mínima exerceu influência em três eventos, com associações negativas e de consideráveis magnitudes com as fenofases inflorescência seca $\left(\mathrm{r}=-0,6247^{* *}\right)$ e cacho recém fecundado $\left(\mathrm{r}=-0,4499^{* *}\right)$, sendo positiva com o evento cacho com frutos imaturos $(\mathrm{r}=0,4492 * *)$. A temperatura média apresentou alta associação positiva com a fenofase inflorescência seca $(\mathrm{r}=0,5672 * *)$ e negativa e de média magnitude com a de cacho seco $\left(\mathrm{r}=-0,2633^{*}\right)$. A umidade relativa do ar influenciou negativamente a fenofase emissão de bráctea $(\mathrm{r}=$ 0,2816*) e de cacho com frutos imaturos $(-0,3036)$. A insolação afetou apenas a taxa de ocorrência de cacho recém fecundado sendo, porém, de baixa magnitude $(\mathrm{r}=-0,2770)$.

Conforme resultados da análise do índice de sincronia para as fenofases de floração e frutificação do patauazeiro, os índices foram baixos, o que indica que a palmeira pode ser classificada como assincrônica, ou seja, poucos indivíduos manifestam a fenofase ao mesmo tempo. Estudo realizado em inajazeiro (Attalea maripa) nas condições de Bonito-PA também 
teve baixo nível de sincronia (Pires et al., 2016), sendo que os autores justificaram este fato como sendo consequência do longo período de floração e frutificação da espécie. O que pode ser explicado para a espécie em foco nas condições do estudo.

Tabela 2. Estimativas de correlação simples (Pearson) obtidas entre as taxas de ocorrências dos sete eventos fenológicos em patauazeiro (O. bataua) cultivado no município de Belém, PA e as seis variáveis meteorológicas.

\begin{tabular}{ccccccc}
\hline $\begin{array}{c}\text { Fenofases/ Var. } \\
\text { Climáticas }\end{array}$ & $\begin{array}{c}\text { INS } \\
(\mathrm{hr})\end{array}$ & $\begin{array}{c}\text { PREC } \\
(\mathrm{mm})\end{array}$ & $\begin{array}{c}\text { TMAX } \\
\left({ }^{\circ} \mathrm{C}\right)\end{array}$ & $\begin{array}{c}\text { TMIN } \\
\left({ }^{\circ} \mathrm{C}\right)\end{array}$ & $\begin{array}{c}\text { TMED } \\
\left({ }^{\circ} \mathrm{C}\right)\end{array}$ & $\begin{array}{c}\text { URA } \\
(\%)\end{array}$ \\
\hline BRA (\%) & 0,2516 & $-0,2016$ & 0,1375 & 0,1444 & $-0,115 \mathrm{n}$ & $-0,2816^{*}$ \\
IFF $(\%)$ & 0,0264 & $-0,0218$ & 0,113 & 0,0862 & $-0,0299$ & $-0,1286$ \\
IS (\%) & $-0,0252$ & $-0,0558$ & 0,0523 & $-0,6247^{* *}$ & $0,5672^{* *}$ & 0,0765 \\
CRF (\%) & $-0,2770^{*}$ & 0,2179 & $-0,2355$ & $-0,4499^{* *}$ & 0,2506 & 0,2745 \\
CFI (\%) & 0,2353 & $-0,2217$ & 0,1305 & $0,4492^{* *}$ & $-0,2344$ & $-0,3036^{*}$ \\
CM (\%) & $-0,2602$ & 0,2211 & $-0,1542$ & $-0,0180$ & $-0,1063$ & 0,1766 \\
CS $(\%)$ & $-0,2006$ & 0,1781 & $-0,1587$ & $-0,0176$ & $-0,2633^{*}$ & 0,0623 \\
\hline
\end{tabular}

INSO: Insolação (horas); PREC: Precipitação (mm); URA: Umidade relativa do ar (\%); TMD: temperatura média $\left({ }^{\circ} \mathrm{C}\right)$; TMX: Temperatura máxima $\left({ }^{\circ} \mathrm{C}\right)$; TMN: Temperatura mínima $\left({ }^{\circ} \mathrm{C}\right)$; BRA: Emissão de brácteas (\%); IF: Emissão de inflorescências (\%); IS: Emissão de inflorescência seca; CRF: Emissão de cacho recém-fecundado (\%); CFI: Emissão de cacho com fruto imaturo (\%); CFM: Emissão de cacho maduro (\%); CS: Emissão de cacho seco (\%).

Fonte: Autores (2021).

No patauazeiro foram observadas flutuações (negativas/positivas) entre as associações dos eventos fenológicos com as variáveis meteorológicas. A temperatura mínima foi positiva para cacho com frutos imaturos, temperatura média positiva para inflorescência seca, a umidade relativa do ar negativa para emissão de bráctea e cacho com frutos imaturos, a insolação positiva para todas as fenofases, exceto com o evento cacho recém-fecundado. Em outros estudos de padrão fenológico do patauá poucos consideraram como fator influente a umidade relativa do ar e a insolação, em vista dessas variáveis climáticas não exibirem distinção clara dentro dos eventos (Rojas-Robles; Stiles, 2009). Esses autores ressaltaram que a fenologia do patauá apresenta variação dentre os anos assim como as variações climáticas.

Neste trabalho pode-se considerar a hipótese de Alencar (2004) para o comportamento fenológico do patauazeiro, de que não somente são afetados por fatores climáticos, mas também pelas condições endógenas da espécie e vetores ecológicos (apud Rojas-Robles; Stiles, 2009). Logo, as fenofases reprodutivas (floração e frutificação) do patauazeiro ocorrem com picos ao longo do ano, tendendo a florar nos meses de baixa precipitação pluviométrica e frutificar nos meses mais chuvosos.

As estimativas dos autovalores associados aos componentes principais demonstraram que os três primeiros componentes foram responsáveis por explicar 69,95\% da variação total (Tabela 3), sendo que o restante da variação $(30,05 \%)$ representou os dez demais componentes. Com base nas estimativas dos autovetores junto a dos autovalores foi possível identificar as variáveis representantes desses três componentes, sendo elas: a umidade relativa do ar (URA) com a mais alta contribuição, para variação do componente principal 1, com valores semelhantes para insolação (INS) e precipitação (PREC) constituindo o mesmo componente juntos, somam 34,35\% da variação. O segundo componente principal foi formado pela inflorescência seca (IS), junto com temperatura média (T.MED), que somam 20,79\% da variação, já o CP3 teve a maior contribuição do cacho seco (CS), seguido do cacho com fruto maduro (CFM) com contribuição de 15,81\% da variação. Esses resultados permitem sugerir que o patauazeiro possui influência das variáveis climáticas URA, INSO, PREC no comportamento fenológico nas condições do município, contudo está influencia e baixa como analisada na correlação de 
Pearson, devendo ser investigada conjuntamente a conhecimentos ecológicos ao longo dos ciclos subsequentes da espécie no município.

Tabela 3. Estimativas dos autovalores associados aos componentes principais obtidos para 13 variáveis, sendo seis meteorológicas e sete fenológicas, em patauazeiro (O. bataua) cultivado nas condições de Belém, PA.

\begin{tabular}{lrrr}
\hline & CP1 & CP2 & CP3 \\
\hline BRA & $-0,142$ & 0,043 & 0,450 \\
IFF & $-0,057$ & 0,027 & 0,299 \\
IS & 0,158 & $\mathbf{- 0 , 4 8 8}$ & 0,143 \\
CRF & 0,240 & $-0,281$ & 0,296 \\
CFI & $-0,225$ & 0,229 & 0,095 \\
CFM & 0,161 & $-0,007$ & $\mathbf{0 , 5 0 1}$ \\
CS & 0,097 & 0,115 & $\mathbf{0 , 5 4 8}$ \\
INSO & $\mathbf{- 0 , 4 3 1}$ & $-0,204$ & 0,021 \\
PREC. & $\mathbf{0 , 4 1 6}$ & 0,253 & $-0,036$ \\
T.MAX & $-0,404$ & $-0,272$ & 0,043 \\
T.MIN & $-0,277$ & 0,426 & 0,048 \\
T.MED & 0,136 & $\mathbf{- 0 , 4 7 6}$ & $-0,144$ \\
URA & $\mathbf{0 , 4 3 7}$ & 0,169 & $-0,118$ \\
\hline Var. total $(\%)$ & 33,35 & 20,79 & 15,81 \\
\hline
\end{tabular}

Fonte: Autores (2021).

O padrão fenológico do patauazeiro na condição do estudo demonstrou floração e de frutificação em todos os meses do ano (Figura 6), com sobreposição de picos em dois meses (novembro e dezembro). Os eventos de floração tiveram as maiores ocorrências, com pico de outubro a dezembro, englobando os meses menos chuvosos. Enquanto as fenofases de frutificação, apesar de terem ocorrido também ao longo do ano, foram mais frequentes de novembro a fevereiro, com o pico mostrando tendência para o período chuvoso.

\section{Conclusão}

A fenologia reprodutiva do patauazeiro nas condições do estudo ocorre em todos os meses, sendo os eventos assincrônicos e com sobreposição entre os picos floração e os de frutificação, caracterizando a espécie como de reprodução supra anual. As variáveis meteorológicas exercem influência pouco significativas na maioria dos eventos de floração e de frutificação. Recomenda-se para melhores resultados de padrão fenológico considerar o estudo das variáveis endógenas da espécie.

Para trabalhos futuros sugere-se a obtenção do número de cachos colhido e a produção de frutos por planta, além da produtividade de frutos por ciclo na condição do estudo, para obtenção de dados mais completos. 
Figura 6. Padrão fenológico do patauazeiro (O. bataua) cultivado nas condições de Belém, PA, obtido a partir das taxas de ocorrências mensais de três eventos de floração e de quatro de frutificação, no período de setembro/2014 a março/2019.

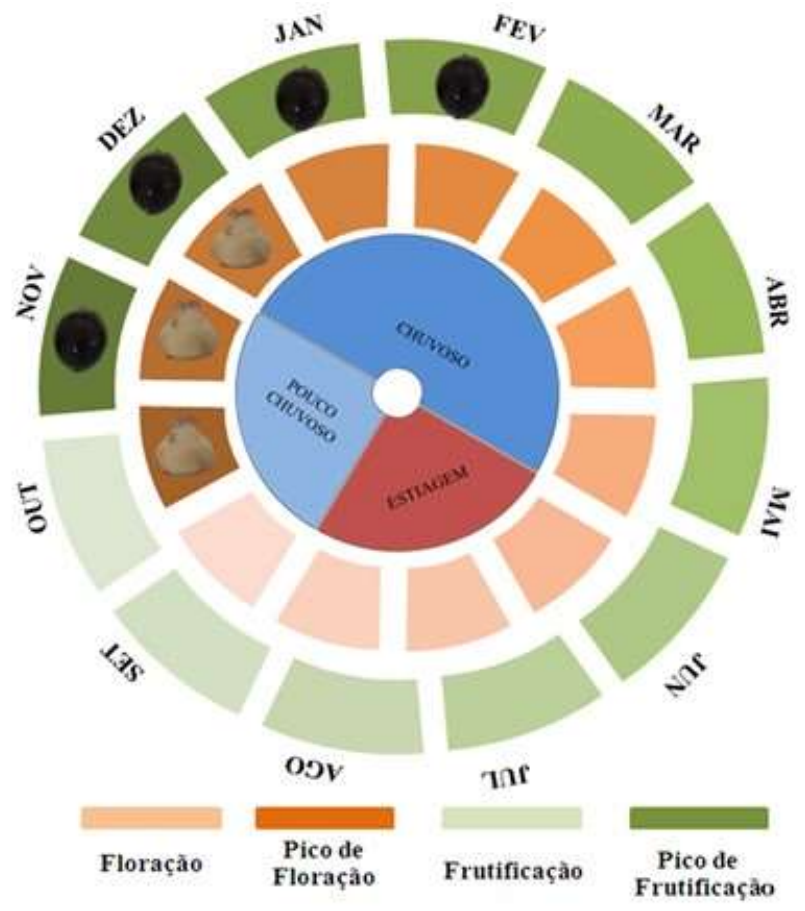

Fonte: Autores (2021).

\section{Referências}

Bencke, C. S. C., \& Morellato, L. P. C. (2002). Estudo comparativo da fenologia de nove espécies arbóreas em três tipos de floresta atlântica no Sudeste do Brasil. Revista Brasileira de Botânica, 25(2), 237-248. https://doi.org/10.1590/S0100-84042002000200012

Bergamaschi, H. (2007). O clima como fator determinante da fenologia das plantas. Fenologia: ferramenta para conservação, melhoramento e manejo de recursos vegetais arbóreos. Embrapa Florestas, Colombo, 291-310.

Cifuentes, L., Moreno, F. H., \& Arango, D. A. (2010). Fenologia reprodutiva e produtividade de frutos de Oenocarpus bataua (Mart.) em florestas inundadas na região biogeográfica de Chocó, Colômbia. Biota Neotropica. 10 (4), 101-110. https://doi.org/10.1590/S1676-06032010000400014

Collazos, M. E., \& Mejía, M. (1988). Fenología y poscosecha de mil pesos Jessenia bataua (Mart) Burret. Acta Agronómica. 38 (1), $53-63$.

Costa, S. A., \& Lameira, O. A. (2021). Avaliação do comportamento fenológico da Copaifera martii (Hayne) com dados climáticos em Floresta Secundária. Research, Society and Development, 10 (9), e41810917973-e41810917973. http://dx.doi.org/10.33448/rsd-v10i9.17973

Cruz, C. D. (2006). Programa Genes: Biometria. Editora UFV. 382.

D'Eça-Neves, F. F., \& Morellato, L. P. C. (2004). Métodos de amostragem e avaliação utilizados em estudos fenológicos de florestas tropicais. Acta Botânica Brasílica, (18), 99-108. http:// dx.doi.org/10.1590/S0102-33062004000100009

Duarte, O. R., Oliveira, J. M. F. de, Schwengber, D. R., Ferreira, L. M. M., \& Filho Melo, A. A. de. Inajá. In: Lopes, R.; Oliveira, M. do S. P. de; Cavallari, M. M.; Barbieri, R. L.; Conceição, L. D. H. C. S. da. (2015.) Palmeiras nativas do Brasil. Embrapa, cap. 8. 249-267.

EMBRAPA Recursos Genéticos E Biotenologia. Alelo. http://alelobag.cenargen.embrapa.br/AleloConsultas/Home/index.do> .

Figueiredo Filho, D. B., \& Silva Júnior, J. A. da. (2009). Desvendando os Mistérios do Coeficiente de Correlação de Pearson (r). Revista Política Hoje, (18), 115-146. http:// dx.doi.org/10.11606/issn.2237-4485.lev.2014.132346

Garcia, V. A., \& Barbedo, C. J. (2016). Estudo fenológico de Bactris gasipaes Kunth, Euterpe edulis Mart. e Syagrus romanzoffiana (Cham.) Glassman no Vale do Ribeira, SP, Brasil. Hoehnea, 43 (1), 135-149. https://doi.org/10.1590/2236-8906-40/2015

Gomes-Silva, D. A. P., Wadt, L. H de O., \& Ehringhaus, C. (2004). Ecologia e manejo de patauá (Oenocarpus bataua Mart.) para produção de frutos e óleo. Embrapa Acre-Documentos (INFOTECA-E).

INMET - Instituto Nacional de Meteorologia. Dados climatológicos de precipitação e temperatura do Município de Oeiras do Pará, PA. (2016) http://www.inmet.gov.br/projetos/rede/pesquisa/gera_serie_txt_mensal.php?\&mRelEstacao=8263\&btnProcesso=serie\&mRelDtInicio=01/01/2016\&mRelDtFi $\mathrm{m}=30 / 11 / 2016 \& \mathrm{mAtributos}=,,,,,,,, 1,,,, 1,,,>$

Isaza, C., Martorell, C., Cevallos, D., Galeano, G., Valencia, R., \& Balslev, H. (2016). Demography of Oenocarpus bataua and implications for sustainable 
Research, Society and Development, v. 10, n. 11, e376101119627, 2021

(CC BY 4.0) | ISSN 2525-3409 | DOI: http://dx.doi.org/10.33448/rsd-v10i11.19627

harvest of its fruit in western Amazon. Population ecology, 58 (3), 463-476. https://doi.org/10.1007/s10144-016-0543-4

Lima, J. M. T., Caruso, N. M., Clugston, J., \& Kainer, K. A. (2018). A mudança de paisagem altera a fenologia reprodutiva e a expressão sexual em palmeiras de Attalea (Arecaceae) no sudoeste da Amazônia. Ecologia de plantas, 219 (10), 1225-1245. https://doi.org/10.1007/s11258-018-0874-7

Mantovani, M., Ruschel, R. A., Reis, M. S., Puchalski, A., \& Nodari, R. O. (2003). Fenologia reprodutiva de espécies arbóreas em uma formação secundária da floresta atlântica. Revista Árvore, 27 (4), 451-458. https://doi.org/10.1590/S0100-67622003000400005

Mendes, F. N., Valente, R. M., Rêgo, M. M. C., \& Esposito, M. C. (2017). Reproductive phenology of Mauritia flexuosa L.(Arecaceae) in a coastal restinga environment in northeastern Brazil. Brazilian Journal of Biology, 77 (1), 29-37. https://doi.org/10.1590/1519-6984.08515

Miller, C. (2002). Fruit production of the ungurahua palm (Oenocarpus bataua subsp. bataua, Arecaceae) in an indigenous managed reserve. Economic Botany, 56 (2), 165-176. https://doi.org/ 10.1663 / 0013-0001

Miranda, J., Montaño, F., Zenteno, F., Nina, H., \& Mercado, J. (2008). El Majo (Oenocarpus bataua): una Alternativa de Biocomercio en Bolivia. TRÓPICO PNBS - FAN. Ediciones TRÓPICO. La Paz, Bolivia. 2008.

Morellato, L. P. C., Alberton, B., Alvarado, S. T., Borges, B., Buisson, E., Camargo, M. G. G., Cancian, L. F., Carstensen, D. W., Escobar, D. F. E., Leite, P. T. P., Mendoza, I., Rocha, N. M. W. B., Soares, N. C., Silva, T. S. F. S., Staggemeier, V. G., Streher, A. S., Vargas, B. C., \& Peres, C. A. (2016). Linking plant phenology to conservation biology. Conservation Biology. 195, 60-72. https://doi.org/10.1016/j.biocon.2015.12.033

Mushtaq, M., Akram, S., \& Hasany, S. M. (2019). Seje (Oenocarpus/Jessenia bataua) Palm Oil. In: Fruit Oils: Chemistry and Functionality. Springer, Cham, p. $883-898$

Pereira, A. S., Shitsuka, D. M., Parreira, F. J., \& Shitsuka, R. (2018). Metodologia da pesquisa científica. UFSM. 119p.

Pires, H. C. G., Santos, R. L. dos, Cabral, B. S., Silva, V. M. da, Nogueira, G. A., \& Ferreira, P. R. N. (2016). Padrão Fenológico de Attalea maripa (Aubl.) Mart. em Áreas de Pastagens na Amazônia Oriental. Floresta e Ambiente, 23 (2), 170-179. https://doi.org/10.1590/2179-8087.048313

Rojas-Robles, R., \& Stiles, F. G. (2009). Análise de um ciclo supra-anual: fenologia reprodutiva da palma Oenocarpus bataua em uma floresta dos Andes colombianos. Jornal de Ecologia Tropical, 25 (1), 41-51. https://doi.org/10.1017/S026646740800552X

Ruiz, R. R., \& Alencar, J. da C. (2004). Comportamento fenológico da palmeira patauá (Oenocarpus bataua) na reserva florestal Adolpho Ducke, Manaus, Amazonas, Brasil. Acta Amazônica, Manaus, 34 (4), 553-558. https://doi.org/10.1590/S0044-59672004000400007

Silva, J. Z., \& Reis, M. S. (2018). Fenologia reprodutiva e produção de frutos em Euterpe Edulis (Martius). Ciência Florestal, 28 (1), 295-309. https://doi.org/10.5902/1980509831655

Serra, J. L., Cruz Rodrigues, A. M. da, Freitas, R. A. de, Almeida-Meirelles, A. J. de, Darnet, S. H., \& Silva, L. H. M. da. (2019). Fontes alternativas de óleos e gorduras de plantas da Amazônia: ácidos graxos, metil-tocóis, carotenóides totais e composição química. Food research international, $116,12-19$. https://doi.org/10.1016/j.foodres.2018.12.028 